\title{
Evaluasi Program Deteksi Dini Kanker Serviks dengan Metode See and Treat di Kabupaten Karawang
}

\author{
Berland Budiman, Yudi Mulyana Hidayat, Ali Budi Harsono \\ Departemen Obstetri dan Ginekologi Fakultas Kedokteran Universitas Padjadjaran \\ Rumah Sakit Dr. Hasan Sadikin Bandung \\ Korespondensi: Berland Budiman, Email: budimanberland@gmail.com
}

\begin{abstract}
Abstrak
Tujuan: Kanker serviks merupakan jenis kanker terbanyak nomor dua di kalangan perempuan di Indonesia setelah kanker payudara. Kanker serviks dikenal dengan "silent killer" karena perkembangannya yang sulit dideteksi. Metode see and treat dengan pemeriksaan Inspeksi Visual Asam Asetat (IVA) dan tindakan segera jika ditemukan IVA positif menggunakan krioterapi merupakan upaya untuk menurunkan angka kejadian dan mortalitas yang disebabkan kanker serviks. Tujuan penelitian ini adalah untuk melakukan evaluasi pelaksanaan program deteksi dini kanker serviks di Kabupaten Karawang dari dimulainya pelaksanaan program pilot project dari tahun 2007 hingga sekarang.

Metode: Desain penelitian menggunakan metode mixed method. Rancangan penelitian kuantitatif dengan metode potong lintang dan rancangan penelitian kualitatif dengan melakukan wawancara dengan panduan open-ended question.

Hasil: Dari hasil penelitian variabel yang paling berpengaruh terhadap komponen input adalah sumber daya manusia dan dukungan pemerintah berupa pendanaan, pada komponen proses adalah variabel pelaksanaan dan monitoring evaluasi, sedangkan pada variabel output sasaran target program masih jauh dari yang diharapkan.

Kesimpulan: Dapat disimpulkan bahwa program deteksi dini kanker serviks dengan metode see and treat di Kabupaten karawang masih kurang optimal. Dibutuhkan sumber daya manusia yang baik secara kualitas dan kuantitas, ketersediaan sarana dan prasarana, dukungan pemerintah yang optimal, dan sosialisasi masyarakat untuk menunjang keberhasilan program.
\end{abstract}

Kata kunci: Evaluasi program, Kanker serviks, see and treat

\section{Evaluation of Early Detection of Cervical Cancer with See and Treat Method in Karawang Regency}

\begin{abstract}
Objective: Cervical cancer is the second most common cancer among women in Indonesia after breast cancer. Cervical cancer is known as the "silent killer" because its development is difficult to detect. The see and treat method with IVA examination and immediate action if a positive IVA was found using cryotherapy is an attempt to reduce the incidence and mortality caused by cervical cancer. The purpose of this research is to explore the implementation of early detection program of cervical cancer in Kabupaten Karawang from the beginning of pilot project implementation from year 2007 until now.

Method: The research design used mixed method. The design of quantitative research with cross sectional method and qualitative research design by conducting an interview with open-ended question guide.

Result: From the results of research, the most influential variables on the input components are human resources and government support in the form of funding, the component of the process is the implementation and evaluation variables evaluation, while the target output variable target program is still far from expected.

Conclusion: It can be concluded that early detection program of cervical cancer with see and treat method in Karawang district is not optimal. Good human resources needed in quality and quantity, availability of facilities and infrastructure, optimal government support, and socialization of the community to support the success of the program.
\end{abstract}

Keywords: Cervical cancer, program evaluation, see and treat 


\section{Pendahuluan}

Di Indonesia diperkirakan 52 juta perempuan Indonesia berisiko terkena kanker serviks, sementara $36 \%$ perempuan dari seluruh penderita kanker adalah pasien kanker serviks. Ada 15.000 kasus baru kanker serviks terjadi dengan angka kematian 7.500 kasus per tahun. Kanker serviks merupakan kanker yang paling sering terjadi pada perempuan Indonesia. Tingginya angka kejadian kanker serviks di Indonesia merupakan beban kesehatan, ekonomi dan sosial bagi perempuan dimanapun. Insidensi kanker serviks menurut perkiraan DEPKES, 100 per 100.000 penduduk pertahun, sedangkan data dari laboratorium patologi anatomi seluruh Indonesia, frekuensi kanker serviks paling tinggi diantara kanker yang ada di Indonesia, penyebarannya terakumulasi di Pulau Jawa dan Bali. ${ }^{1}$

Pemerintah telah melakukan program dalam mengendalikan kanker serviks mencanangkan suatu program single visite approach yang bertujuan untuk mencegah kanker serviks dan penyakit menular seksual. Program ini didanai dan dibuat oleh pemerintah Belanda melalui penggalangan dana penyakit kanker di Universitas Leiden pada tahun 2004-2006, dengan berbagai provinsi dan kota di Indonesia, bekerja sama dengan Universitas Indonesia dan Rumah Sakit Cipto Mangunkusumo di Jakarta, Universitas Padjadjaran dan Rumah Sakit Hasan Sadikin di Bandung, Universitas Siliwangi dan Rumah Sakit Umum di Tasikmalaya, juga Universitas Udayana dan Rumah Sakit Sanglah di Bali. Program ini ditujukan kepadawanitayang tinggal di daerah yang akses terhadap fasilitas kesehatannya terbatas. Target wanita yang akan dilakukan skrining berusia 20-60 tahun, dan ditargetkan $80 \%$ wanita dari setiap daerah tersebut. Dari data yang didapatkan, terdapat total 22.040 wanita yang dilakukan pemeriksaan Inspeksi Visual Asam Asetat (IVA), 7480 (33,9\%) berasal dari Jakarta, 8007 (36,3\%) berasal dari Tasikmalaya dan $6553(29,7 \%)$ berasal dari Bali. Secara keseluruhan, 92,7\% wanita tersebut belum pernah dilakukan skrining sebelumnya dan sepertiganya hidup dibawah garis kemiskinan. Dari total 22.040 wanita, didapakan 970 orang $(4,4 \%)$ IVA positif dan $19(0,1 \%)$ orang dicurigai kanker serviks. Dari hasil yang didapatkan program tersebut, deteksi dini kanker serviks dengan metode see and treat lebih representative untuk diterapkan di negara berkembang seperti di Indonesia. ${ }^{1}$

Untuk melaksanakan program
ini Departemen Kesehatan telah menyelenggarakan pilot project deteksi dini kanker serviks di 6 kabupaten di Indonesia, yaitu di Deli serdang, Gresik (Jawa Timur), Kebumen (Jawa Tengah), Gunung Kidul (Daerah Istimewa Yogjakarta), Gowa (Sulawesi Selatan) dan di Jawa barat sendiri Kabupaten Karawang. ${ }^{2}$ Departemen Kesehatan Republik Indonesia (Depkes RI) melaporkan rata-rata pencapaian skrining kanker serviks di 6 daerah pilot project adalah 11,64\%. Target ini masih jauh dari target yang ditetapkan WHO sebesar $80 \%$. WHO merekomendasikan, bahwa keberhasilan program skrining kanker serviks minimal $80 \%$ dari populasi wanita yang berisiko berusia 30-50 tahun. ${ }^{2}$ Karena alasan di atas, penulis tertarik untuk mengetahui faktorfaktor yang menghambat keberhasilan program deteksi dini kanker serviks terutama di Kabupaten Karawang sebagai pilot project program see and treat di Jawa Barat. Hasil penelitian ini diharapkan menjadi penelitian pendahuluan yang berguna sebagai acuan bagi daerah lain terutama di Jawa Barat yang belum melaksanakan program deteksi dini kanker serviks.

Kabupaten Karawang secara geografis berada di bagian utara Provinsi Jawa Barat, dengan luas wilayah $\pm 1.753,27 \mathrm{~km}^{2}$ atau $3,73 \%$ dari luas Provinsi Jawa Barat yang terdiri dari 30 kecamatan dengan jumlah 
desa seluruhnya 297 desa dan 12 kelurahan. Jumlah puskesmas di Kabupaten Karawang tahun 2015 tercatat sebanyak 50 puskesmas, terdiri dari 37 puskesmas tanpa perawatan dan 13 puskesmas dengan perawatan. Proporsi puskesmas terhadap penduduk di Kabupaten Karawang sebesar 1:45.472, hal ini masih di bawah target nasional sebesar 1:30.000, sedangkan jumlah puskesmas pembantu tercatat sebanyak 71 buah. Menurut data laporan indeks diagnosis pasien Rumah Sakit Umum Daerah Karawang periode 1 Januari 2013 sampai dengan 30 Desember 2013 ditemukan kasus sebanyak 83 pasien penderita kanker serviks dan periode 1 Januari sampai dengan 30 Desember 2014 ditemukan sebanyak 91 kasus. $^{3}$

\section{Metode}

Penelitian ini adalah suatu penelitian yang menggunakan metode campuran (mixed method) antara penelitian kuantitatif dan kualitatif dengan pilihan desain explanatory sequential, yaitu metode penelitian campuran yang dimulai dengan tahap pertama berupa pengumpulan data kuantitatif kemudian dilanjutkan dengan pengumpulan data kualitatif. Metode kuantitatif menggunakan data sekunder yang sudah ada dari Dinas Kesehatan Kabupaten Karawang, sedangkan metode kualitatif menggunakan wawancara terfokus dengan panduan open-ended question. Kuestioner yang digunakan kepada pengguna program, digunakan untuk mengukur skala sikap dengan menggunakan skala Likert untuk menilai kepuasan pengguna program dalam hal ini masyarakat yang telah melakukan pemeriksaan IVA tes. Data yang diperoleh dari hasil wawancara, catatan lapangan dan rekaman suara disusun peneliti di lokasi. Peneliti segera melakukan analisis data dengan memperkaya informasi, mencari hubungan, menemukan pola atas dasar data aslinya. Hasil analisis data berupa pemaparan mengenai situasi yang diteliti yang disajikan dalam bentuk uraian naratif.

\section{Hasil}

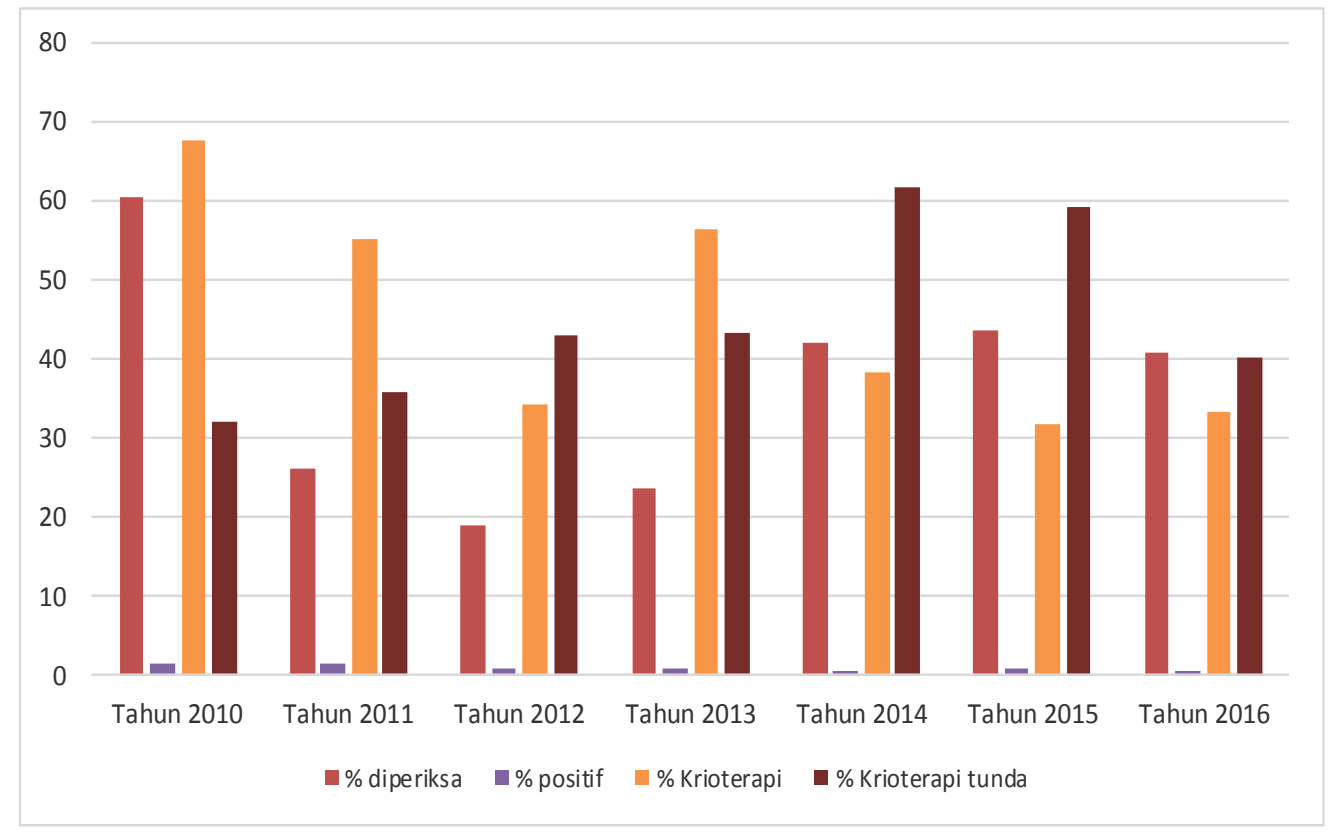

Gambar 1 Rerata \% yang Diperiksa, \% Positif, \% yang di Krioterapi dan \% Krioterapi Tertunda dari tahun 2010 sampai dengan Tahun 2016 
Dari gambar tampak terjadi fluktuasi persentase Wanita Usia Subur (WUS) yang melakukan pemeriksaan IVA tes, tahun 2010 yang melakukan IVA tes sebanyak $60,5 \%$, terus menunjukkan penurunan sampai tahun 2013 menjadi $23,7 \%$, kemudian naik kembali menjadi $43,6 \%$ pada tahun 2015 , dan pada tahun 2016 turun lagi menjadi 41,0\%.

Selanjutnya, untuk persentase positif hasil pemeriksaan IVA tes tampak terjadi penurunan dari $1,5 \%$ pada tahun 2010 menjadi $0,4 \%$ pada tahun 2016.

Dari hasil IVA tes yang positif ini tidak semua dilanjutkan dengan melakukan tindakan krioterapi, untuk tahun 2010 yang dilakukan krioterapi sebesar $67,8 \%$, dan terus menunjukkan penurunan tahun 2016 menjadi $33,2 \%$; sisanya dilakukan penundaan. Hanya saja penundaan tidak dicatat kapan akan dilakukan tindakan krioterapi berikutnya.

Hal ini peneliti mencoba menggali permasalahan yang terjadi pada pelaksanaan deteksi dini penyakit kanker serviks, sehingga akan dapat memberikan rekomendasi yang berguna bagi dinas kesehatan setempat dalam penanggulangan penyakit kanker serviks di masyarakat.

Hasil penelitian kualitatif menggunakan Komponen Input Evaluasi Program See and Treat. Implementasi program see and treat pada pusat pelayanan kesehatan memerlukan peran berupa tenaga pelaksana yaitu orang yang bertanggung jawab dan mengkoordinir jalannya program. Dari hasil wawancara dengan beberapa informan dapat disimpulkan bahwa sumber daya manusia masih sangat kurang dan tim pelaksana program see and treat rata-rata double job dengan program yang lain

Berdasarkan hasil penelitian terkait pelaksana program see and treat, bahwa tenaga pelaksana yang terlibat yaitu bidan dan dokter umum yang telah dilatih. Hal tersebut sesuai dengan pedoman yang ada di Permenkes No. 34 tahun 2015 bahwa yang boleh melaksanakan adalah bidan dan dokter yang sudah mendapatkan pelatihan mengenai IVA tes dan krioterapi.

\section{Pembahasan}

Berdasarkan hasil penelitian yang berkaitan dengan SDM, hampir di seluruh puskesmas pelaksana program see and treat di Kabupaten Karawang telah mendapatkan pelatihan, namun tidak semua dokter dan bidan yang ada di puskesmas diberikan pelatihan. Permasalahan sumber daya manusia diperparah lagi dengan menurunnya fungsi dan peran dokter dalam program see and treat sebagai konsultan apabila terdapat kasus yang perlu dilakukan konsultasi dan pemeriksaan selanjutnya. Adanya pemberlakuan mutasi terhadap dokter dan bidan di puskesmas juga turut berkontribusi dalam menurunnya kualitas pelayanan program see and treat. Seringkali program yang awalnya sudah berjalana baik, menjadi terhambat karena adanya tenaga kesehatan terlatih yang pindah ke sarana puskesmas lain yang belum melaksanakan program see and treat di Puskesmas kabupaten Karawang. Selain itu, pelaksana program yang juga memiliki tugas lebih dari satu sebagai pemegang program lain.

Tingginya target sasaran WUS yang tidak ditunjang dengan jumlah SDM yang memadai, menjadikan beban kerja yang tinggi bagi pelaksana program see and treat di Puskesmas. Ketersediaan sumber daya manusia kesehatan sangat mempengaruhi keberhasilan pembangunan kesehatan.

Pengadaan sumber daya manusia kesehatan bertujuan untuk menetapkan jumlah dan jenis tenaga yang sesuai dengan kebutuhan pelaksana deteksi dini kanker leher rahim. Sumber daya manusia merupakan aset yang sangat vital, karean itu keberadaanya dalam suatu program tidak dapat digantikan dengan sumber daya lainnya. Betapapun modern teknologi yang digunakan atau seberapa banyak dana yang disiapkan, namun 
tanpa dukungan sumber daya manusia yang memiliki kemampuan profesional semuanya menjadi tidak bermakna. ${ }^{3}$

Berdasarkan hasil penelitian yang diungkapkan oleh informan, untuk sarana yang bersifat alat dan bahan pendukung pemeriksaan seperti meja ginekologi, lidi $s w a b$, spekulum dan sebagainya untuk melaksanakan pemeriksaan sudah cukup memadai dan dalam keadaan baik. Hal tersebut sesuai dengan hasil observasi yang dilakukan oleh peneliti bahwa alat dan bahan yang digunakan dalam keadaan lengkap dan baik serta sesuai sehingga tidak mengalami kendala dalam melaksanakan pemeriksaan. Pengadaan alat dan bahan untuk pemeriksaan dikelola sendiri oleh masing-masing puskesmas.

Alat krioterapi sebagai terapi bagi pasien yang ditemukan IVA positif hanya dimiliki oleh 8 puskesmas saja, padahal sejak awal program berlangsung pada tahun 2007 terdapat 16 alat yang didanai oleh JHPIEGO, tetapi dengan berbagai alasan, terdapat kerusakan alat yang tidak dapat diperbaiki karena mahalnya biaya perbaikan dan tidak tersedianya dana khusus yang dianggarkan oleh Dinas Kesehatan Kabupaten Karawang sebagai penanggung jawab program. Pada beberapa puskesmas, petugas juga mengaku belum berani menggunakan alat tersebut karena belum mendapatkan pelatihan menggunakan alat krioterapi, sehingga apabila ditemukan IVA positif di rujuk ke puskesmas terdekat yang memberikan pelayanan krioterapi atau langsung dirujuk ke rumah sakit.

Pelaksanaan suatu program selalu membutuhkan berbagai sarana dan prasarana yang mendukung sehingga program tersebut dapat terlaksana sesuai dengan yang telah direncanakan. Tanpa ketersediaan sarana dan prasarana, suatu kegiatan tidak dapat dilaksanakan sebagaimana seharusnya, bahkan akan mengalami hambatan atau tidak berjalan dengan lancar. Sarana dan prasarana merupakan seperangkat alat yang digunakan untuk proses kegiatan salah satunya dalam pelaksanaan program deteksi dini kanker serviks dengan metode see and treat ${ }^{4}$

Dalam implementasi suatu program, dana merupakan salah suatu sumber daya yang sangat penting dalam menunjang keberhasilan sebuah program. Dana harus digunakan secara maksimal dan efektif agar tujuan awal suatu program dapat tercapai. Hasil penelitian kualitatif yang didapatkan dari hasil wawancara terhadap informan didapatkan bahwa puskesmas tidak memiliki alokasi dana khusus untuk menjalankan program see and treat, padahal saat awal program pencegahan kanker serviks dengan metode see and treat ini dimulai di Kabupaten Karawang didanai oleh JHPIEGO sejak awal tahun 2007 hingga 2012, seluruh kegiatan program pengayaan alat dan bahan seperti alat krioterapi, bahan habis pakai, media promosi seperti lembar balik, leaflet dan poster difasilitasi. Sejak periode JHPIEGO berakhir, keberlangsungan program dijalankan oleh pihak Dinas Kesehatan Kabupaten Karawang. Terdapat dua sumber dana yang ada dipuskesmas kabupaten karawang, yaitu dana kapitasi dan Bantuan Operasional Kesehatan (BOK). Dengan adanya dana kapitasi puskesmas, permasalahan kebutuhan peralatan termasuk kebutuhan peralatan kegiatan pemeriksaan IVA seperti spekulum dapat teratasi. Pemerintah pusat melalui Undang-undang nomor 33 tahun 2004 tentang perimbangan keuangan antara pemerintah pusat dan pemerintah daerah mengamanatkan Dana Alokasi Khusus sebagai salah satu sumber pembiayaan bagi daerah untuk meningkatkan pembangunan kesehatan, sehingga pemerintah pusat dan pemerintah daerah dapat menyediakan pelayanan kesehatan yang merata, terjangkau dan berkualitas. ${ }^{(5)}$

Berakhirnya pendanaan oleh JHPIEGO dan dialihkanya ke APBD sangat dirasakan oleh informan. Informasi yang didapat 
dari kepala puskesmas sebagai pemegang kebijakan menyatakan diperlukan dana untuk operasional kegiatan program see and treat, sehingga dengan perubahan sumber dana serta keterbatasan dana, saat ini kepala puskesmas mengambil kebijakan dengan memberikan biaya tarif pemeriksaan diluar gedung. Pasien yang melakukan pemeriksaan IVA, dibebaskan dari biaya pemeriksaan apabila memiliki kartu BPJS namun bagi yang tidak memiliki kartu BPJS dikenakan biaya Rp25.000. Biaya yang harus ditanggung oleh pasien non BPJS ini cukup memberatkan bagi pasien. Pada tahun 2017 ini pemerintah daerah melalui Dinas Kesehatan Kabupaten Karawang menganggarkan biaya sebesar Rp183.000.000 untuk pelaksanaan program see and treat dimana dana digunakan untuk program pelatihan bagi Puseksmas yang belum melaksanakan program see and treat, acara gebyar IVA sebagai salah satu sarana promosi, dan evaluasi di akhir tahun.

Sosialisasi adalah proses komunikasi untuk menyampaikan suatu ide atau gagasan kepada suatu kelompok masyarakat agar ide atau gagasan program tersebut dapat diterima oleh sasaran bersama warga masyarakat sekitarnya. Menurut hasil wawancara yang didapatkan dari informan, Sosialisasi program pencegahan kanker serviks dengan metode see and treat biasanya dilakukan di Puskesmas, posyandu, beberapa pengajian dan sekolah, desa, kecamatan hingga kabupaten yang melibatkan lintas sektor dan lintas program serta melibatkan kader, tokoh agama dan tokoh masyarakat. Bentuk sosialisasi yang diberikan berupa risiko dan penyebab serta bahaya kanker serviks, kemudian yang terpenting adalah berupa upaya pencegahan dengan melakukan screening dan pencegahan dengan melakukan deteksi dini kanker serviks. Sosialisasi dan promosi kesehatan pada hakikatnya ialah suatu kegiatan atau usaha menyampaikan pesan kepada masyarakat, kelompok atau individu.dengan adanya pesan tersebut diharapkan masyarakat, kelompok atau individu memperoleh pengetahuan tentang kesehatan yang lebih baik. Pengetahuan tersebut akhirnya diharapkan dapat berpengaruh terhadap perilaku. Dengan kata lain adanya sosialisasi dan promosi kesehatan tersebut dapat membawa akibat terhadap perubahan perilaku sasaran. ${ }^{5}$

Komponen lain yang digunakan adalah Komponen Proses Evaluasi Program Pencegahan Kanker Serviks dengan Metode See and Treat. Perencanaan merupakan suatu proses kegiatan yang urut sebagai suatu upaya untuk menghasilkan keputusan dan tindakan mendasar yang membentuk dan membimbing seperti apa sebuah organisasi, apa yang dilakukan dan mengapa dilakukan dengan memanfaatkan sumber daya yang tersedia secara berhasil guna dan berdaya guna. ${ }^{6}$ Dengan perencanaan yang baik maka fungsi pelaksanaan dan pengawasan akan berjalan baik jika dijalankan sesuai dengan perencanaan yang telah disusun sebelumnya. Perencanaan program pencegahan kanker serviks dengan metode see and treat di Kabupaten Karawang dimulai dengan menentukan jumlah sasaran wanita usia subur di wilayah kerja puskesmas masingmasing, dilanjutkan dengan pendekatan yang strategis agar target program tercapai secara efektif dan efisien. Perencanaan program merupakan langkah awal dalam suatu proses menjalankan suatu program untuk menetapkan dan menyamakan visi, misi, menetapkan tujuan, sasaran dan pencapaian serta bagaimana menjalankan program tersebut dan pada akhirnya mendapatkan output yang diharapkan yaitu meningkatnya jumlah sasaran WUS yang mengikuti program see and treat.

Langkah pertama dalam mekanisme perencanaan tingkat puskesmas adalah dengan penyusunan rencana usulan kegiatan program see and treat. Penyusunan rencana usulan kegiatan puskesmas harus memperhatikan berbagai kebijakan yang 
berlaku baik secara global, nasional maupun daerah sesuai dengan hasil kajian data dan informasi yang tersedia di puskesmas.

Puskesmas perlu mempertimbangkan masukan dari masyarakat melalui berbagai wadah yang ada. Rencana usulan kegiatan harus dilengkapi dengan usulan pembiayaan untuk kebutuhan rutin, sarana prasarana dan operasional. $^{7}$

Alur pemeriksaan yang harus dilakukan oleh pasien pada dasarnya sama dengan alur pada pasien pada umumnya, yaitu terlebih dahulu melakukan pendaftaran, membagikan nomor urut, pembuatan status pasien, pemanggilan pasien untuk masuk ke ruang pemeriksaan, jika pasien datang bersama suami konseling lebih mudah dilakukan kepada keduanya secara bersamaan, informed consent, pemeriksaan IVA, menjelaskan kepada pasien tentang hasil pemeriksaan dan tindakan, bila hasil IVA positive dimintakan informed consent selanjutnya untuk dilakukan krioterapi. Sama halnya dengan hasil penelitian ini, bahwa pelaksanaan kegiatan program IVA sesuai dengan petunjuk teknis tersebut. $^{8}$

Berdasarkan hasil wawancara dengan informan, program see and treat dapat terlaksana walaupun hasilnya belum maksimal, karena adanya komitmen dari Dinas Kesehatan Kabupaten Karawang sebagai penanggung jawab dan dokter serta bidan pelaksana program di Puskesmas untuk melaksanakan program serta meningkatnya kesadaran dan kebutuhan masyarakat akan pentingnya melakukan skrining deteksi dini kanker serviks.

Pengawasan, pengendalian dan evaluasi yang didalamnya termasuk penilaian kinerja dan pelaporan merupakan suatu fungsi manajemen untuk mengetahui dan menjamin kemajuan suatu program atau kegiatan pelayanan, dan untuk menilai hasil akhir dari suatu program ataupun kegiatan pelayanan. Monitoring, pengendalian dan evaluasi sebenarnya merupakan bagian dari fungsi pengawasan dan berkaitan erat dengan modul-modul lain yang menguatkan pelaksanaan semua fungsi manajemen, mulai dari perencanaan, pengorganisasian, penggerakan dan pengawasan itu sendiri. ${ }^{(9)}$

Proses pengawasan kegiatan program pencegahan kanker serviks dengan metode see and treat dikabupaten karawang dengan pemeriksaan IVA dan krioterapi dilakukan secara berjenjang melalui monitoring oleh penanggungjawab pelaksana program di puskesmas, dilaporkan kepada kepala puskesmas setiap bulan menggunakan format laporan khusus, kemudian hasilnya diserahkan kepada dinas Kesehatan kabupaten karawang setiap bulan. Pengawasan juga dilakukan secara langsung oleh tim peninjau dinas kabupaten untuk melakukan evaluasi secara keseluruhan ke puskesmas melalui Standard Based Management and Recognition (SBMR). ${ }^{10}$ Pencatatan dan pelaporan hasil pemeriksaan dan pencapaian target sasaran dilampirkan dalam suatu format yang sama pada seluruh Puskesmas pelaksana program see and treat di Kabupaten Karawang, yang dilaporkan setiap bulan kepada kepala puskesmas yang kemudian dilaporkan ke Dinas Kesehatan Kabupaten Karawang. Dari hasil wawancara, hampir seluruh puskesmas pelaksana program see and treat di Kabupaten Karawang masih dibawah target nasional yaitu $80 \%$, hal ini disebabkan oleh tingginya target sasaran yang tidak sesuai dengan jumlah sumber daya manusia serta fokus kerja pelaksana program yang terbagi dengan program lain yang harus mereka kerjakan. Kurangnya rangsangan berupa dana khusus yang diberikan, sedikit banyak turut berperan terhadap motivasi pelaksana program. Hal terpenting yang menjadi hambatan terbesar menurut informan adalah masih rendahnya tingkat pengetahuan dan kesadaran masyarakat itu sendiri tentang pentingnya melakukan deteksi dini pencegahan kanker serviks dengan melakukan screening sejak awal. 
Dari hasil wawancara kepada penanggung jawab program di Dinas Kesehatan, hampir seluruh penanggung jawab program di puskesmas melaporkan hasil pemeriksaan dan pencapaian target setiap bulan sesuai jadwal, walaupun keterlambatan pelaporan masih sering dilakukan oleh beberapa puskesmas. Adanya format yang baku turut membantu memudahkan pelaksana program see and treat untuk melakukan pelaporan evaluasi, sehingga pihak Dinas Kesehatan lebih mudah dan cepat dalam mengelola laporan.

Komponen Output Evaluasi Program See and Treat Pencegahan Kanker Serviks di Kabupaten Karawang digunakan untuk melihat pencapaian target program see and treat tentang pencegahan deteksi dini kanker serviks di Kabupaten Karawang telah dilakukan dengan mengumpulkan data yang lengkap dari periode tahun 2010 sampai dengan tahun 2016. Dari data yang tersedia berisi tentang target wanita usia subur per tahun yang harus diperiksa, realisasi jumlah yang diperiksa, hasil positif pemeriksaan IVA, dan persentase yang dilakukan krioterapi, serta persentase yang tertunda krioterapi masih jauh dibawah target yang diharapkan.

Kepuasan Pengguna Program dinilai berdasarkan hasil pengolahan yang disajikan, dapat disimpulkan bahwa skor total untuk variabel Q1 sampai Q9 adalah 1436. Jumlah skor tersebut dimasukan ke dalam garis kontinum yang pengukurannya dilakukan dengan cara :

- Nilai Indeks Maksimum $=4 \times 44 \times 9$ $=1584$

- Nilai Indeks Minimum $=1 \times 44 \times 9=$ 396

- $\quad$ Persentase Skor $=1436: 1584 \times 100 \%$ $=90,6 \%$

Berdasarkan data tersebut dapat digambarkan melalui analisis garis kontinum sebagai berikut:

\section{Persentase terhadap Q1 sampai Q9 dalam Garis Kontinum}

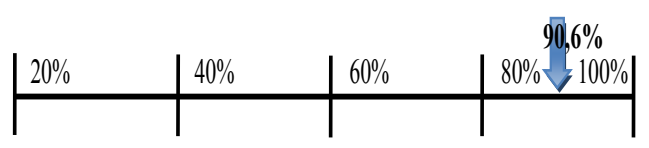

\section{Persentase Seluruh Indikator Q1 sampai Q9 dalam Garis Kontinum}

Kepuasan pasien juga menjadi penilaian dalam penelitian ini. Hasil survey terhadap 44 responden berdasarkan persentase diatas menunjukkan nilai yang diperoleh dari tanggapan responden adalah sebesar 1436 atau sebesar 90,6\%. Hasil penelitian menyebutkan pasien merasa puas terhadap pelayanan dan nyaman dengan pemeriksaan yang didapatkannya. Simpulan, Berdasarkan hasil pembahasan ada beberapa kriteria yang dianggap belum maksimal dalam pelaksanaan program see and treat, yaitu belum tercapainya target dari pelaksanaan program pada tahun 2016 baru mencapai target $50 \%$.

Hal ini terjadi karena ada beberapa faktor diantaranya kurangnya pengembangan Sumber daya manusia sehingga pada pelaksanaan program adanya ketidaksesuaian antara Sumber Daya Manusia yang ada dengan target sasaran, pelaksana program yang tidak dapat fokus karena memiliki tanggung jawab sebagai pelaksana program yang lain, kurangnya dukungan pemerintah berupa dana untuk pengayaan alat terutama krioterapi, dan sosialisasi terhadap masyarakat yang masih kurang maksimal tentang pentingnya melakukan pemeriksaan deteksi dini kanker serviks. Pengawasan program yang dirasakan kurang baik oleh pelaksana program di puskesmas juga turut menyebabkan menurunnya motivasi dalam pelaksanaan program deteksi dini kanker serviks. Dengan demikian diperlukan keterlibatan semua pihak yang bertanggungjawab dalam keberlangsungan program dalam rangka pencapaian target yang optimal. 


\section{Daftar Pustaka}

1. Vet JN, Kooijman JL, Henderson FC, Aziz FM, Purwoto G, Susanto H, et al. Single- visit approach of cervical cancer screening: see and treat in Indonesia. Br J Cancer. 2012;107(5):772-7.

2. Depkes R. Profil Kesehatan Indonesia 2008. Jakarta: Depkes RI. 2009.

3. Yuniarsih, Tjutju, Suwatno. Manajemen sumber daya manusia 1ed. Bandung: Alfabeta; 2013.

4. Mursyid H. Pelaksanaan Program Usaha Sekolah di Dinas Kesehatan Pemerintah Kota Medan Tahun 2003 [Skripsi]. Medan: Universitas Sumatera Utara.; 2003.

5. Departemen Kesehatan RI. Petunjuk Teknis Penggunaan Dana Alokasi Khusus Bidang Kesehatan, serta Sarana dan Prasarana Penunjang Subbidang Sarpras Kesehatan Tahun Anggaran 2016. Jakarta: Depkes RI; 2016.

6. Notoatmodjo S. Promosi kesehatan dan ilmu perilaku. 2 ed. Jakarta: Rineka Cipta; 2007.

7. Masyarakat IDKDJBK. Pedoman perencanaan tingkat puskesmas. Jakarta: Direktorat Jenderal Bina Kesehatan Masyarakat; 2015.

8. Kemenkes R. Panduan program nasional gerakan pencegahan dan deteksi dini kanker leher rahim dan kanker payudara. RI K, editor. Jakarta: Direktorat Pengendalian Penyakit Tidak Menular; 2015.

9. Indonesia DKR. Pedoman manajerial pencegahan dan pengendalian infeksi di rumah sakit dan fasilitas pelayanan kesehatan lainnya. Jakarta: Departemen Kesehatan RI; 2008.

10. Parkin D. National Cancer Control Planning. Indonesian Journal of Cancer. 2008;3(suppl. 2):1-4. 